\title{
Biodesulfurization of dibenzothiophene by Shewanella putrefaciens NCIMB 8768
}

\author{
Farahnaz. Ansari ${ }^{1 *}$, Pum. Prayuenyong ${ }^{2}$ and Ibtisam. Tothill ${ }^{3}$ \\ ${ }^{1}$ Microsystems \& Nanotechnology Centre, Department of Materials, Cranfield University, \\ Bedfordshire MK43 OAL, UK \\ ${ }^{2}$ Institute of Bioscience \& Technology, Cranfield University, Cranfield Beds MK43 OAL, UK \\ ${ }^{3}$ Cranfield Health, Cranfield University, Bedfordshire MK43 OAL, UK \\ *Corresponding author. E-mail: $\underline{\text { f.ansari@ cranfield.ac.uk }}$ \\ Journal of Biological Physics and Chemistry 7 (2007) 75-78 @ 2007 Collegium Basilea \& \\ AMSI
}

Received 25 May 2007; accepted 15 June 2007

The desulfurization ability of Shewanella putrefaciens strain NCIMB 8768 was studied and its activity profile was compared with the widely studied strain Rhodococcus erythropolis strain IGTS8. Dibenzothiophene (DBT) is a recalcitrant thiophenic component of fossil fuels especially among diesel blend stocks. DBT in basic salt medium (BSM) at a final concentration of $0.3,0.6$ and $0.9 \mathrm{mM}$ was supplied to the microbes as the sole sulfur source. Experimental results showed that S. putrefaciens, similar to other biodesulfurization organisms, converted DBT to the end product 2-hydroxybiphenyl (HBP), as detected by the Gibbs assay and HPLC. Cells cultivated in medium containing $0.3 \mathrm{mM}$ of DBT showed the highest desulfurization activity, with a maximum specific production rate $43.5 \mathrm{mmol} / \mathrm{L}$ of $\mathrm{HBP}$.

Keywords: biodesulfurization, dibenzothiophene, Shewanella putrefaciens. 


\section{INTRODUCTION}

Clean fuel research, including into improvement of the processes of desulfurization and dearomatization, has become an important focus of environmental catalysis studies worldwide. Sulfur contained in diesel fuel is an environmental concern because the sulfur is converted to SO $x$ during combustion, which not only contributes to acid rain, but also poisons the catalytic converters now widely installed for exhaust emission treatment. The problem of sulfur removal has become more apparent due to the high sulfur contents in crude oils and the low limit of sulfur content in finished fuel products specified by regulatory authorities. The Environmental Protection Agency of the United States (EPA) had set a target to reduce the sulfur content of diesel fuel from $500 \mathrm{ppm}$ to $15 \mathrm{ppm}$ for the year 2006 and $10 \mathrm{ppm}$ will become the maximum content for sulfur by 2008 (Yang et al., 2005). Thiols, sulphides and thiophenes are readily removed by hydrodesulfurization (HDS), but up to $70 \%$ of the sulfur in petroleum is found as DBT and substituted (methylated) DBTs, which are particularly recalcitrant to HDS treatment compared with mercaptans and sulfides (Yang et al., 2005; Le Borgne et al., 2003). Microbiological methods to desulfurize hydrocarbon streams offer a potentially attractive alternative to traditional chemical engineering methods. Biological processes require relatively mild conditions (low pressures and low temperatures), which could be a major advantage of biodesulfurization. Therefore most studies on biodesulfurization (BDS) have focused on the removal of thiophenic sulfur compounds, of which DBT is widely accepted to be representative. DBT is indeed considered to be particularly relevant as a model compound for the forms of thiophenic sulfur found in fossil fuels, such as crude oils, coals or bitumen of particular geographic origins, and the various refining intermediates and fuel products manufactured therefrom (Olson, 1998). Various bacteria are able to metabolize DBT. In the 1970s, Kodama 
showed that microörganisms could attack DBT without removing sulfur (Scheme 1). This microbial transformation of DBT by the Kodama pathway involves cleavage of one of DBT's aromatic rings so it has not been commercially developed because it did not remove the sulfur atom from the heterocyclic compound, and moreover led to a decrease in the fuel's calorific value through the oxidation of benzene ring.
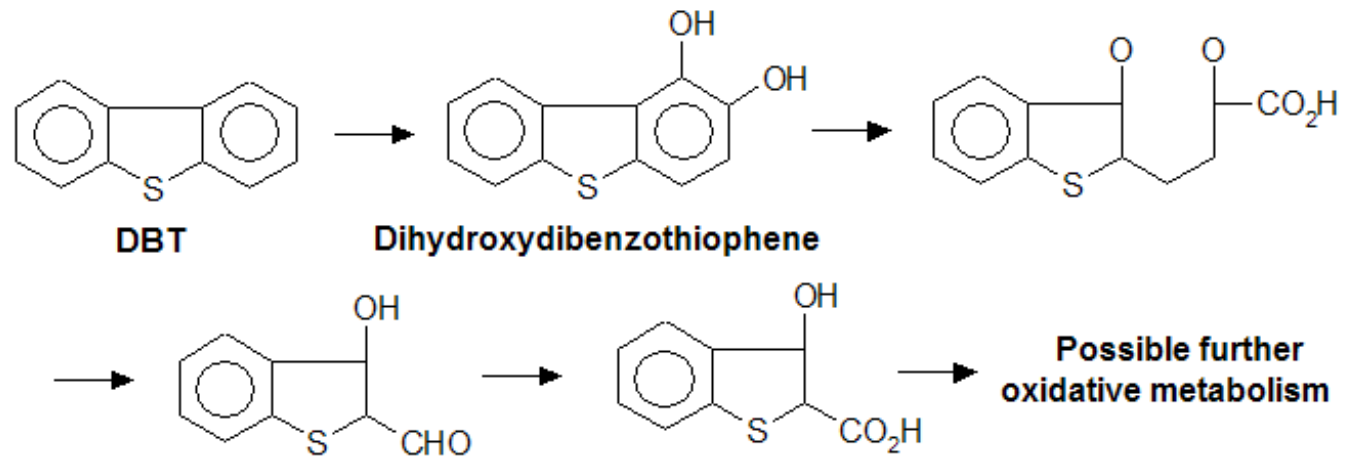

Hydroxy formyl benzothiophene

Scheme 1. Kodama pathway for the degradation of DBT. The product, hydroxyl formyl benzothiophene, retains the sulfur moiety (Kodama et al., 1973).

Another biological pathway that is of interest to researchers involves four enzymatic steps and is therefore called the 4 S pathway (Kilbane 1989). This pathway (Scheme 2) is more interesting for practical applications, since sulfur removal takes place without destruction of the aromatic rings. 

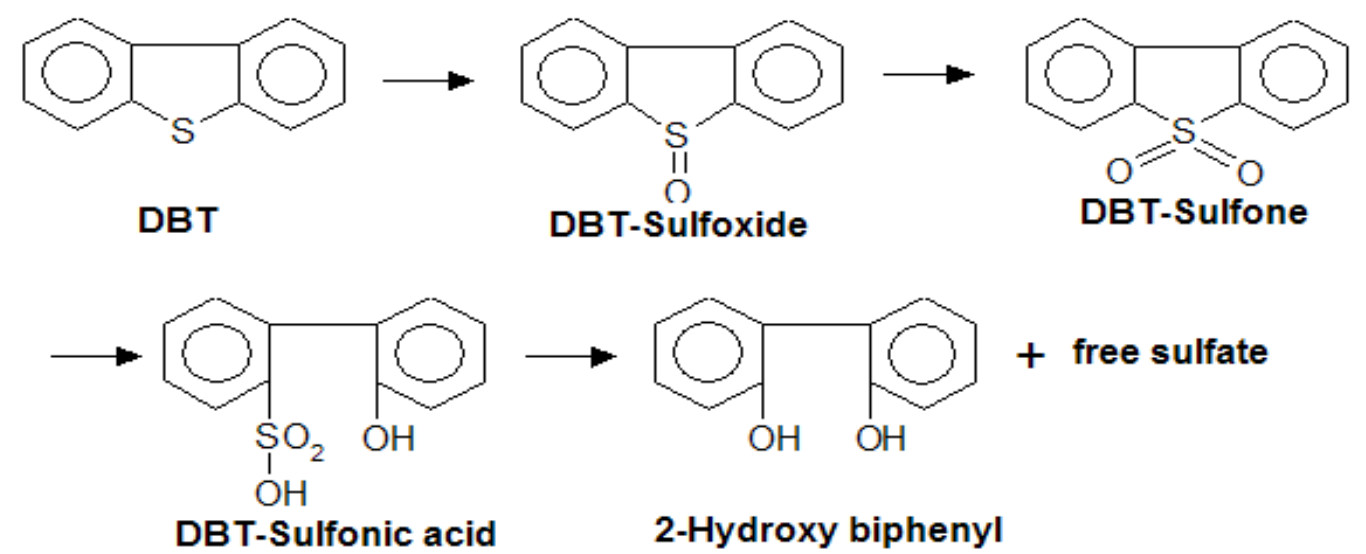

Scheme 2. 4S pathway for DBT desulfurization by $R$. erythropolis IGTS8. The DBT desulfurization pathway results in the formation of 2-hydroxybiphenyl (HBP) and sulfate.

In a previous investigation, it has been found thatusing the bacterium $S$. putrefaciens strain NCIMB 8768 in clay desulfurization, sulfur odour was reduced, and the use of this bacterium for coal desulfurization has been examined (Prayuenyong, 2001). The present study builds on that previous work to study in more detail the desulfurization ability of the bacterium S. putrefaciens, and to compare its biodesulfurization activity profile with that of the widely studied Rhodococcus erythropolis strain IGTS8.

\section{MATERIALS AND METHODS}

\subsection{Chemicals}

Nutrient agar and broth were from Oxoid (UK), dibenzothiophene (DBT) (99\%), dimethyl sulfoxide, 2-hydroxybiphenyl (HBP), Gibbs reagent and all other chemicals were from Fisher Scientific (UK). Water was highly purified by ion exchange and reverse osmosis in an Elga installation. 


\subsection{Bacterial strains}

Shewanella putrefaciens (NCIMB 8768) was purchased from National Collections of Industrial and Marine Bacteria Ltd (Aberdeen, UK). Rhodococcus erythropolis IGTS8 (ATCC 53968) from American Type Culture Collections (Virginia, USA) was used for comparison.

\subsection{Medium and growth conditions}

Basic salt medium (BSM), a sulfur-free medium containing 2.44 g KH2PO4, 5.47 g Na2HPO4, $2.00 \mathrm{~g} \mathrm{NH} 4 \mathrm{Cl}, 0.2 \mathrm{~g} \mathrm{MgCl} 2.6 \mathrm{H} 2 \mathrm{O}, 0.001 \mathrm{~g} \mathrm{CaCl} 2.2 \mathrm{H} 2 \mathrm{O}, 0.001 \mathrm{~g} \mathrm{FeCl} 3.6 \mathrm{H} 2 \mathrm{O}, 0.004 \mathrm{~g}$ $\mathrm{MnCl} 2.4 \mathrm{H} 2 \mathrm{O}$ and $1.84 \mathrm{~g}$ glycerol per litre of deionized water, was used. DBT dissolved in ethanol was added as the sole sulfur source to give final concentrations of $0.3,0.6$ and $0.9 \mathrm{mM}$. Cells were cultivated in $250 \mathrm{~mL}$ flasks containing $100 \mathrm{~mL}$ of medium on a rotary shaker operated at $100 \mathrm{rpm}$ for one week at $30{ }^{\circ} \mathrm{C}$.

\subsection{Resting cell reaction}

Cells were grown until the mid-exponential growth phase and harvested by centrifugation (Hettick-EBA 20- Germany) at $6000 \mathrm{rpm}$ for $15 \mathrm{~min}$. The cell pellets were washed twice with Ringer's solution. The cells were then resuspended in the same solution, giving $A 600=1.0$, and used on the day of harvesting. One $\mathrm{mL}$ of inoculum was added to $250 \mathrm{~mL}$ flasks containing 100 $\mathrm{mL}$ of BSM with $0.3 \mathrm{mM}$ of DBT-ethanol solution and incubated at $30{ }^{\circ} \mathrm{C}$ (shaking at $100 \mathrm{rpm}$ ).

\subsection{Detection methods}

Growth was monitored via optical density at $600 \mathrm{~nm}$; the concentration of cells was determined from the linear relationship between OD600 and cell concentration (Stanier, 1976) while dry 
weights were determined after washing cultures three times with Ringer's solution and drying in a $100{ }^{\circ} \mathrm{C}$ oven until a constant weight was obtained. Determination of HBP and DBT was carried out by Gibb's assay and high-performance liquid chromatography (HPLC). All experiments were done in triplicate.

\subsubsection{Gibb's assay}

Desulfurization activity was monitored using the Gibb's reagent (2,6-dichloroquinone-4chloroimide) to detect the 2-hydroxybiphenyl (HBP) produced from DBT. Gibb's reagent reacts with the aromatic hydroxyl groups at $\mathrm{pH} 8$ to form a blue complex that can be monitored spectrophotometrically at $610 \mathrm{~nm}$ after $30 \mathrm{~min}$ incubation at room temperature (Kayser et al., 1993). Briefly the assay consists of the following steps: aliquots $(5 \mathrm{~mL})$ of culture broth are centrifuged (1200 rpm, $10 \mathrm{~min})$ to remove cells. The supernatant $(2 \mathrm{~mL})$ was then transferred to an Eppendorf tube. $0.1 \mathrm{~g}$ Gibb's reagent was dissolved in $10 \mathrm{~mL}$ absolute ethanol in a test tube, and $20 \mu \mathrm{L}$ were added to each Eppendorf tube containing $2.0 \mathrm{~mL}$ supernatant adjusted to $\mathrm{pH} 8$. The assays were incubated at $30{ }^{\circ} \mathrm{C}$ for 30 minutes to complete the colour development. The absorbance of the supernatant was determined at $610 \mathrm{~nm}$ and converted to HBP concentration based on a standard curve (Monticello, 1993).

\subsubsection{HPLC}

The concentration of DBT and HBP were analysed by high-performance liquid chromatography using a Shimadzu HPLC Model LC-10AD VP equipped with a Nova Pak phenyl column $(3.9 \times$ $150 \mathrm{~mm}$ ) together with a guard column. Elution was isocratic with $60 \%$ acetonitrile and $40 \%$ water at $1.5 \mathrm{~mL}$ min-1, and detection used a $117 \mathrm{UV}$ detector fixed at wavelength $=233 \mathrm{~nm}$. The 
mobile phase, a mixture of HPLC grade water and acetonitrile, was sonicated for 10 minutes and further degassed with helium before use.

\section{RESULTS AND DISCUSSION}

Biodesulfurization activity comparison: both strains grew in BSM+DBT and produced HBP DBT degradation (Figure 1). The DBT concentration was halved after 3 days incubation. HBP analysis confirmed that similarly to $R$. erythropolis, $S$. putrefaciens desulfurized DBT through the selective cleavage of the C-S bonds, resulting in the accumulation of HBP. The detection of HBP when Shewanella utilized DBT as the sole sulfur source suggests that the DBTdesulfurizing pathway is the so-called 4S pathway as proposed by Kilbane et al. (1992) for degradation using Rhodococcus.

This type of reaction is desirable for practical desulfurization since the sulfur atom is removed without $\mathrm{C}-\mathrm{C}$ bond cleavage, that is, without loss of calorific energy. The amounts of HBP produced and DBT degraded of $R$. erythropolis were not quite equivalent however (Figure 1) (Kayser et al., 1993).

It has been reported that HBP is toxic to bacterial cells; hence biodesulfurization will be inhibited by accumulation of HBP (Zhang et al., 2005). This is a complicating factor in our batch experiments, i.e. that the end product HBP is somewhat inhibitory to cell growth and possibly therefore to desulfurization activity. 

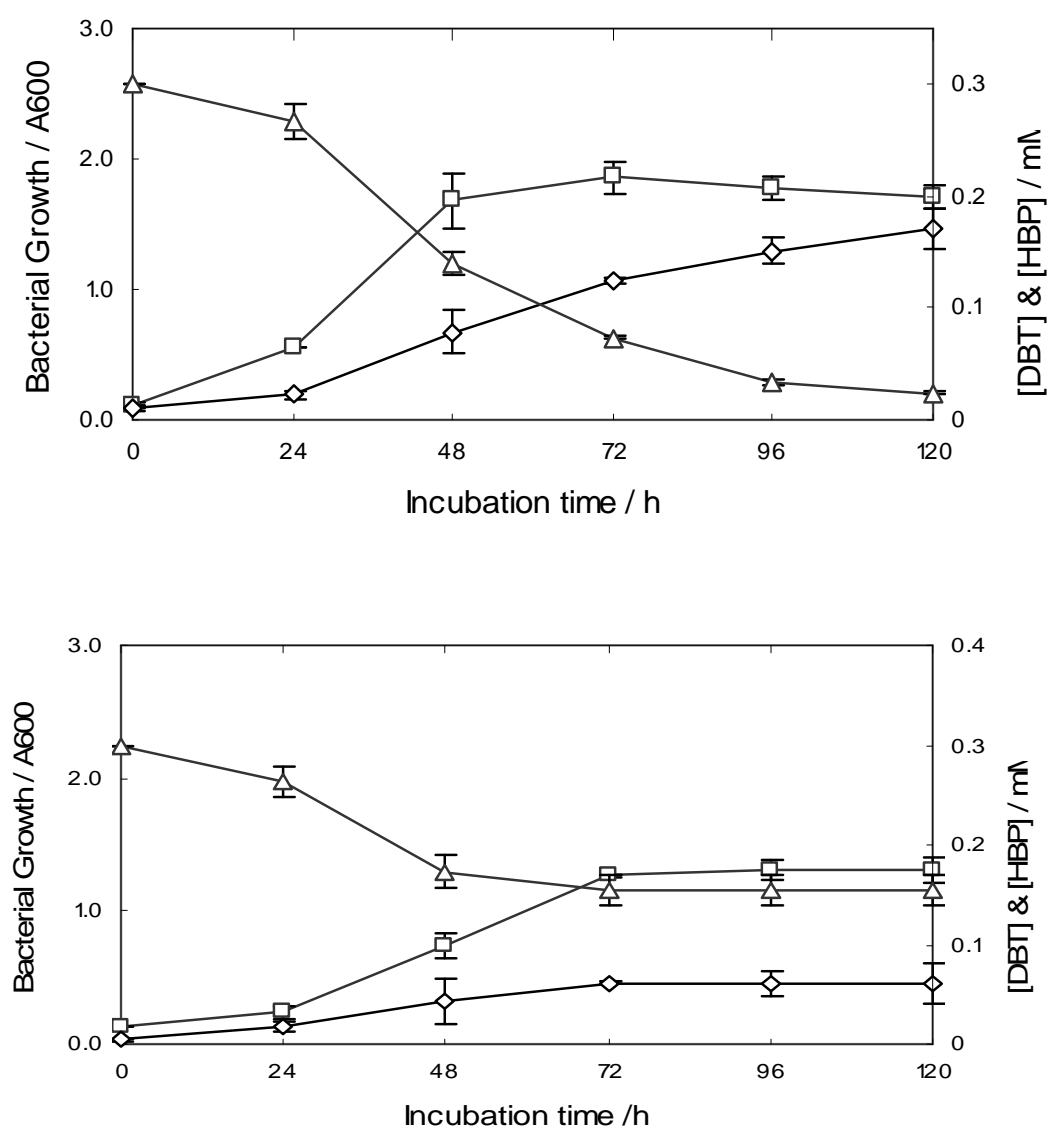

Figure 1. DBT desulfurization by (A) R. erythropolice IGTS8, and (B) S. putrefaciens NCIMB in DBT at a concentration of $0.3 \mathrm{mM}$ as the sole sulfur source. Key: $\square$, bacterial growth; $\square$, concentration of HBP; $\square$, concentation of DBT.

Effect of DBT concentration (Figure 2): S. putrefaciens could only grow in BSM medium with DBT at an initial concentration of $0.3 \mathrm{mM}$ as the sole sulfur source. At higher concentrations, bacterial growth was inhibited, presumably because the bacteria could not tolerate the high concentration of what is actually a bacteriotoxin. 

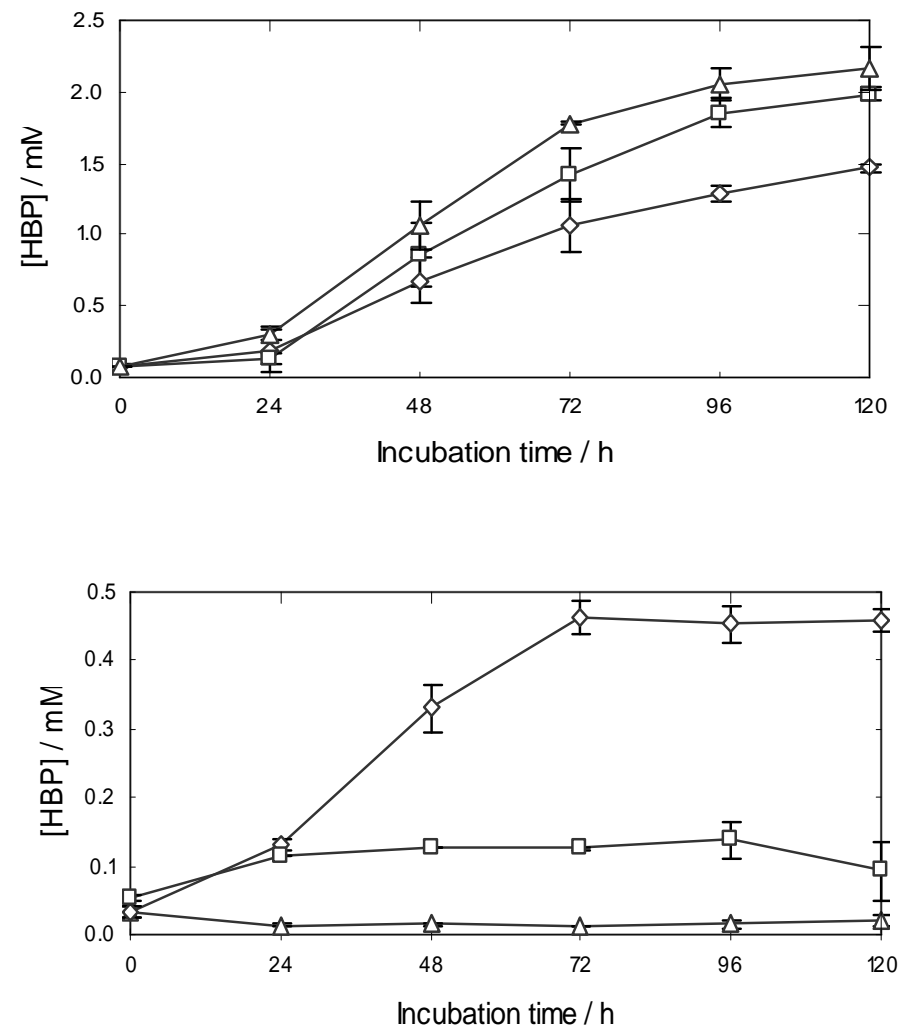

Figure 2. Production of HBP by (A) R. erythropolis and (B) S. putrefaciens at different concentrations of DBT. Key: $\square, 0.3 \mathrm{mM} ; \square, 0.6 \mathrm{mM} ; \square, 0.9 \mathrm{mM}$.

\section{CONCLUSION}

Shewanella putrefaciens showed desulfurization activity and detection of HBP in the culture medium is evidence that this strain desulfurized DBT via the $4 \mathrm{~S}$ pathway. Therefore, $S$. putrefaciens is a potentially useful desulfurizing bacterium. However, regarding its effectiveness we consider it necessary to confirm what is the rate-limiting step in DBT desulfurization by $S$. putrefaciens, as a first step towards determining whether the genes encoding the DBT desulfurizing enzymes of Shewanella are different from those of other desulfurizating bacteria such as $R$. erythropolis IGTS8. 
Moreover, more experiments need to be carried out to investigate parameters like $\mathrm{pH}$ and carbon source and enriched media on the growth of the bacteria and their desulfurization activity.

\section{ACKNOWLEDGMENT}

F.A. would like to thank Jeremy Ramsden for his help and guidance in the writing of this paper.

\section{REFERENCES}

Denome, S.A., Oldfield, C., Nash, L.J., and Young, K.D. Characterization of the desulfurization genes from Rhodococcus sp. strain IGTS8. J. Bacteriol. 176 (1994) 6707-6716.

Kayser, K.J., Bielaga-Jones, B.A., Jachowski, K., Odusan, O., Kilbane, J.J. Utilization of organosulfur compounds by axenic and mixed culture of Rhodococcus rhodochrous IGTS8. J. Gen. Microbiol. 139 (1993) 3123 - 3129.

Kilbaine, J. J. Desulfurization of coal: the microbial solution. Trends Biotechnol. 7 (1989) 97101.

Kilbaine, J.J. and Jackowski, K. Biodesulfurization of watersoluble coal-derived material by Rhodococcus rhodochrous IGTS8. Biotechnol. Bioengng 40 (1992) 1107-1114.

Kodama, K., Nakatani, S., Umehara, K., Shimizu, K., Minoda, Y., and Yamada, K. Microbial conversion of petro-sulfur compounds. Part III, Isolation and identification of products from dibenzothiophene. Agric. Biol. Chem. 34 (1970) 1320-1324.

Kodama K., Umehara K., Shimizu K., Nakatani S., Monioda Y., Yamada K. Identification of microbial products from dibenzothiophene and its proposed oxidation pathway. Agric. Biol. Chem. 37 (1973) 45-50.

Le Borgne, S. and Quintero, R. Biotechnology processes for the refining of petroleum. Fuel Processing Technology 81 (2003) 155- 169.

Monticello, D.J. Continuous process for biological desulfurization of sulfur-bearing heterocyclic molecules. United States Patent 5472875 (1993). 
Monticello, D.J. Process for the desulfurization and the desalting of a fossil fuel. United States Patent 5356813 (1992).

Prayuenyong, P. Biodesulfurization. Cranfield University (unpublished thesis) (2001).

Stanier, R.Y., Adelberg, E.A. and Ingraham, J.L. General Microbiology, 4th edn, pp. 275-292. London: Macmillan (1976).

Yang, J. and Marison, I.W. Two-stage process design for the biodesulfurization of a model diesel by a newly isolated Rhodococcus globerulus. DAQ3. Biochem. Engng J. 27 (2005) 77-82.

Wei Li, Ying Zhang, Miao Dong Wang and Yao Shi Biodesulfurization of dibenzothiophene and other organic sulfur compound by newly isolated Mycobacterium strain ZD-M2. FEMS Microbiol. Lett. 247 (2005) 45-50. 